\title{
Impact of oscillatory-cycloid vibration interventions on body composition, waist and hip circumference, and blood lipid profile in women aged over 65 years with hypercholesterolaemia
}

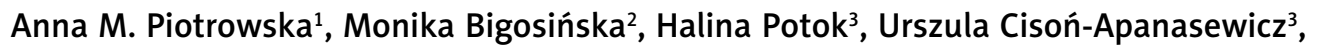 \\ Olga Czerwińska-Ledwig ${ }^{1}$, Łukasz M. Tota ${ }^{4}$, Roxana Zuziakk ${ }^{1}$, Tomasz Pałka ${ }^{4}$, Wanda Pilch ${ }^{1}$ \\ ${ }^{1}$ Department of Biochemistry and Basics of Cosmetology, Faculty of Rehabilitation, University of Physical Education, Krakow, Poland \\ 2Department of Physical Education, Institute of Physical Culture, State Higher Vocational School in Nowy Sacz, Nowy Sacz, Poland \\ ${ }^{3}$ Department of Internal and Social Nursing, Institute of Health, State Higher Vocational School in Nowy Sacz, Nowy Sacz, Poland \\ ${ }^{4}$ Faculty of Physical Education and Sport, University of Physical Education in Krakow, Krakow, Poland
}

\begin{abstract}
Introduction: Vibration therapy interventions are an attractive alternative for people with contraindications to physical activity or manifesting kinesiophobia; they constitute an equivalent to physical activity.

Material and methods: A group of female volunteers with hypercholesterolemia (LDL over $3 \mathrm{mmol} / \mathrm{l}$ ) aged over 65 years were randomized into 2 subgroups: the study group (taking part in interventions on mattresses generating oscillatory-cycloid vibrations) and the control group (receiving interventions on placebo mattresses). All the subjects underwent two 30-minute interventions 5 times a week for the period of 21 days, in the prone position. Before the intervention and after completing the series of sessions, body composition and waist and hip circumferences were assessed. Venous blood for biochemical studies was collected before the intervention, one day after its completion, and one week after completing the series of vibration sessions. On the basis of the lipid profile results, atherogenicity indices were calculated.

Results: After 21 days, a statistically significant decrease in the level of total cholesterol and LDL cholesterol was observed in subjects who received oscillatory-cycloid vibration therapy. No statistically significant changes were noted in the concentrations of HDL cholesterol or triglycerides. The 21-day therapeutic intervention also resulted in lowering the AIP in the study group, as well as a decrease of hip circumference.

Conclusions: Oscillatory-cycloid vibration applied regularly for a longer time can beneficially impact on lowering the level of total cholesterol and LDL cholesterol in people with hypercholesterolemia, although it does not influence body composition in women aged 65 years or more.
\end{abstract}

Key words: therapeutic use of vibration, hypercholesterolemia, LDL cholesterol, atherogenic indices.

\section{Introduction}

Cardiovascular diseases invariably remain the main reason for death in Poland and worldwide; the issue is especially significant among post-menopausal women, when oestrogens cease to fulfil their vasoprotective function and to ensure appropriate rheological blood properties [1]. Atherosclerosis risk factor control constitutes a basic daily challenge for various healthcare professionals. The modifiable risk factors include smoking, lack of physical activity, improper dietary habits, arterial hypertension, type 2 diabetes, and lipid disorders. Lipid profile abnormalities refer to all age groups, and the NATPOL study conducted by Zdrojewski et al. [2] re- vealed that they occurred in up to $61 \%$ of the population, i.e. in ca. 18 million Poles. Dyslipidaemia may also result from the applied medicinal agents, and research proves that the number of patients with polypharmacy increases with age [3]. The treatment of dyslipidaemia is based on diet and on changing other (modifiable) risk factors. If these prove to be inefficient, pharmacotherapy is applied [4]. In some patients, vibration therapy interventions can be helpful. They are an attractive alternative for people with contraindications to physical activity or manifesting kinesiophobia, i.e. a psychological blockade against starting exercise. Kinesiophobia is most frequently observed in orthopaedic patients and 
those with chronic pain syndromes, as well as among peri- and post-menopausal women [5].

Vibration can be applied in treatment under the condition of using stimuli with specific parameters, such as frequency, amplitude, time, and propagation method. In research concerning interventions in healthy individuals and those with various health problems, whole body vibration (WBV) is most comprehensively described [6]. Vibration activates muscle spindles, causing their contraction: tonic vibration reflex [7]. Vibration therapy can be applied in patients with neurological [8], orthopaedic [9], and pulmonary [10] disorders.

The available findings allow us to conclude that an appropriately selected form of vibration intervention can have a beneficial impact on the level of blood plasma lipids [11, 12]. However, the literature referring to the issue is scarce. Moreover, there are considerable methodological discrepancies concerning, most frequently, the vibration parameters and the form of stimulus propagation. This inspired the authors to perform a study with the direct aim of determining the influence of 21-day vibration therapy on body composition, waist and hip circumferences, and lipid profile among women aged over 65 years, with an initial LDL cholesterol concentration equal to or higher than $3 \mathrm{mmol} / \mathrm{l}$.

\section{Material and methods}

\section{Study subjects}

The study was approved by the Ethical Committee of the Regional Medical Chamber in Krakow, Poland (approval No. 155/KBL/OIL/2016). The research involved a group of women aged over 65 years, members of the Third-Age University in Nowy Sacz, Poland, who provided their written consent to participate in the scientific project. A patient flow diagram is presented in Figure 1. The following exclusion criteria were applied:

- stimulant intake (at least in the two-week period before the beginning of the study);

- previous participation in vibration therapy interventions;
- intake of medicinal agents and/or dietary supplements influencing the metabolism of blood plasma lipids;

- negative medical qualification based on contraindications to vibration therapy or general health status;

- high level of physical activity;

- special or elimination diets applied now or up to three months preceding the project.

Prior to the experiment, the participants were informed about its purpose, the applied method, the potential adverse effects, and the possibility to withdraw at any moment without providing a reason. The female volunteers were randomised into two subgroups: the study group ( $n=16$; taking part in interventions on mattresses generating oscillatory-cycloid vibrations) and the control group ( $n=9$; receiving interventions on placebo, non-vibrating mattresses). The subjects documented their dietary details for five days, including one bank holiday, running a photo album of the products and dishes [13]. The diaries were assessed with the use of Dieta 5 software (National Food and Nutrition Institute, Warsaw, Poland). The participants were asked not to change their dietary habits in the course of the study. Their physical activity was determined with the IPAQ shortform questionnaire [14]. The exclusion criterion was physical activity level exceeding 1500 MET min/week.

\section{Vibration therapy interventions}

The scientific research was taken in State University of Applied Sciences in Nowy Sącz. All the study subjects underwent two 30-minute interventions five times a week for a period of 21 days. During each session, the women remained in the prone position. Interventions were applied from Monday to Friday, before noon (between 8.00 and 11.00 a.m. at a fixed time for each participant) in a room with the same temperature and humidity. A rehabilitation massage device, Vitberg+ (Rehabilitacyjny Aparat Masujący Vitberg+, Basic module + Metabolism module), a class Ila medical product, served as the source of vibration. The therapeutic stimulus consisted of cycloid vibrations, produced in three per-

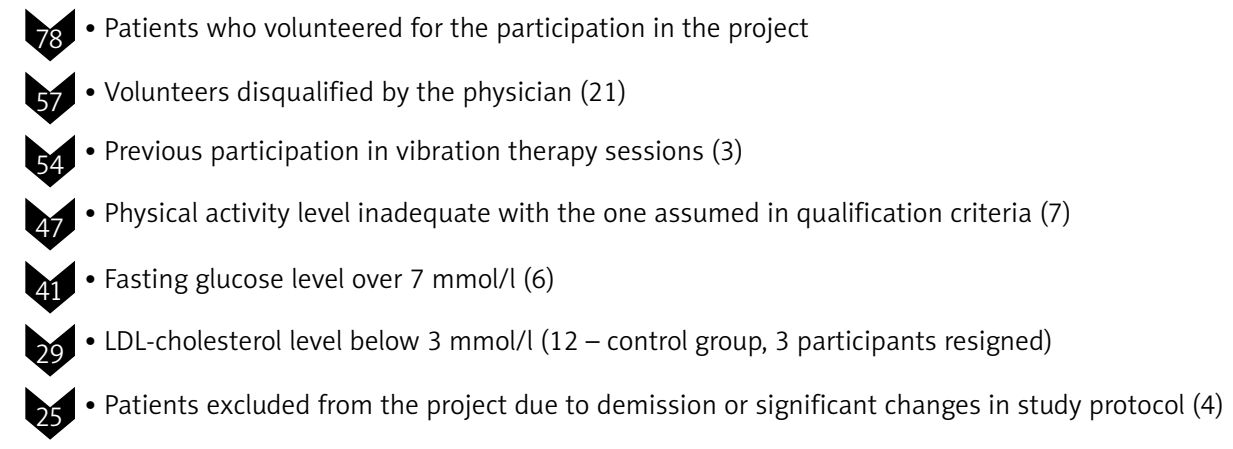

Fig. 1. Patient flow diagram 
pendicular directions (3D), inducing intermittent pulsations with variable values of frequency ( $f$ ), amplitude (A), and acceleration (a), whose ranges were $20-52 \mathrm{~Hz}$, 0.1-0.5 mm, and 6.9-13.5 m/s $\mathrm{s}^{2}$, respectively.

The control group received identical interventions with the use of specially prepared placebo modules (Vitberg, Poland), in which some performance elements had been modified. The placebo device looked and sounded like the active one, which allowed us to maintain blinded group randomisation.

\section{Body composition assessment and biochemical studies}

Before the intervention and on completion of the series, body composition and waist and hip circumferences were assessed. Measurements of the body's circumferences were made using a non-stretchable measuring tape by the same examiner. During the waist circumference measurements, the measuring tape was placed halfway between the lower edge of the last rib and the iliac crest, while maintaining its position parallel to the ground. Hip circumference was measured at the site of the largest convexity of the buttocks below the hip plates. The subjects' body height and body mass, including its components (Prodigy densitometer, GE Healthcare, USA), were determined. On the basis of the body composition, the adipose tissue distribution index was calculated (the percentage ratio of android and gynoid adipose tissue, $A / G$ ratio).

Venous blood for biochemical studies was collected by qualified medical personnel from the vein in the elbow pit before the intervention (day 0), on day 21 in the morning, and after the intervention was completed, each time from a fasting patient, at least 12 hours after the previous meal. Total cholesterol (TC), triglycerides (TG), high-density lipoprotein cholesterol (HDL-C), and low-density lipoprotein cholesterol (LDL-C) were determined in full blood. LDL cholesterol concentrations were calculated using the Friedewald formula (for TG concentrations above $4.6 \mathrm{mmol} / \mathrm{l}$, the result is unreliable; these subjects were excluded from the project):

$$
\begin{gathered}
\mathrm{LDL}-\mathrm{C}=\mathrm{TC}-\mathrm{HDL}-\mathrm{C}-\mathrm{TG} / 2.2 \text { for concentrations } \\
\text { in } \mathrm{mmol} / \mathrm{l}
\end{gathered}
$$

On the basis of the lipid profile results, atherogenicity indices were calculated, which point at cardiovascular risk, i.e. C I (Castelli risk index I): TC/HDL-C; C II (Castelli risk index II): LDL-C/HDL-C; TG/HDL; AIP (atherogenic index of plasma): log (TG/HDL-C); and $A C$ (atherogenic coefficient): TC - HDL-C/HDL-C [15].

\section{Statistical analysis}

Statistical analysis of the results was performed with STATISTICA 13.1 software (StatSoft, Poland). The results are presented as arithmetical means with standard deviations. The Shapiro-Wilk test served to assess distribution normality, and the Levene test to determine the homogeneity of variance. Outliers were rejected on the basis of Grubbs' test. In order to demonstrate the significance of differences between means if the assumptions for parametric tests were met, Student's $t$-test for dependent and independent samples was used, as well as repeated measures analysis of variance (ANOVA) with the post-hoc Tukey test for unequal sample sizes. For the remaining variables, non-parametric tests were applied. The assumed level of significance $(\alpha)$ equalled 0.05 .

\section{Results}

Table 1 presents body composition changes between the pre- and post-intervention time points.

Table 1. General characteristics of the studied women before

\begin{tabular}{|c|c|c|c|}
\hline & Control group & Study group & $p$ \\
\hline \multicolumn{4}{|c|}{ Body mass (kg) } \\
\hline before & $71.26 \pm 8.89$ & $72.32 \pm 6.52$ & \multirow{2}{*}{$\begin{array}{l}0.363 \\
0.198\end{array}$} \\
\hline after & $70.70 \pm 8.22$ & $71.85 \pm 6.32$ & \\
\hline$p^{*}$ & 0.234 & 0.236 & \\
\hline Hight (m) & $158.11 \pm 6.64$ & $160 \pm 7.25$ & 0.257 \\
\hline \multicolumn{4}{|l|}{ BMI } \\
\hline before & $28.46 \pm 2.60$ & $28.20 \pm 2.74$ & \multirow{2}{*}{$\begin{array}{l}0.408 \\
0.351\end{array}$} \\
\hline after & $28.25 \pm 2.37$ & $28.14 \pm 2.74$ & \\
\hline$p^{*}$ & 0.390 & 0.306 & \\
\hline \multicolumn{4}{|l|}{ Fat (g) } \\
\hline before & $29715 \pm 5872$ & $30285 \pm 3550$ & 0.377 \\
\hline after & $29407 \pm 5863$ & $30054 \pm 3903$ & 0.332 \\
\hline$p^{*}$ & 0.386 & 0.166 & \\
\hline \multicolumn{4}{|l|}{ Fat (\%) } \\
\hline before & $42.77 \pm 4.26$ & $43.17 \pm 2.94$ & \multirow{2}{*}{$\begin{array}{l}0.399 \\
0.422\end{array}$} \\
\hline after & $42.62 \pm 5.02$ & $43.01 \pm 3.33$ & \\
\hline$p^{*}$ & 0.206 & 0.450 & \\
\hline \multicolumn{4}{|l|}{ LBM } \\
\hline before & $39372 \pm 3984$ & $39890 \pm 3951$ & \multirow{2}{*}{$\begin{array}{l}0.375 \\
0.401\end{array}$} \\
\hline after & $39201 \pm 4171$ & $39682 \pm 3615$ & \\
\hline$p^{*}$ & 0.207 & 0.274 & \\
\hline \multicolumn{4}{|l|}{ BMC } \\
\hline before & $2090 \pm 379$ & $2128 \pm 242$ & \multirow{2}{*}{$\begin{array}{l}0.375 \\
0.227 \\
\end{array}$} \\
\hline after & $2084 \pm 368$ & $2113 \pm 259$ & \\
\hline$p^{*}$ & 0.332 & 0.263 & \\
\hline
\end{tabular}
and after the series of vibrotherapy treatments

The results are presented as mean values along with standard deviations. $\%$ fat - fat percentage; Fat - fat mass; LBM - lean body mass; BMC - bone mineral content; BMI - body mass index. $p$ (control group vs. study group) $t$-test for independent means, $p^{*}$ (before vs. after) $t$-test for dependent means. 
Table 2. The average energy and basic nutrients content in the diet of the studied women

\begin{tabular}{lccc}
\hline & Control group & Study group & $p$ \\
\hline Energy (kcal) & $1496 \pm 454$ & $1643 \pm 539$ & 0.497 \\
\hline Protein (g) & $75 \pm 27$ & $74 \pm 31$ & 0.487 \\
\hline Carbohydrates (g) & $231 \pm 63$ & $240 \pm 93$ & 0.403 \\
\hline Roughage (g) & $22 \pm 6$ & $23 \pm 10$ & 0.359 \\
\hline Fat (g) & $54 \pm 17$ & $50 \pm 16$ & 0.280 \\
\hline SFA (g) & $20 \pm 4$ & $18 \pm 7$ & 0.309 \\
\hline MUFA (g) & $21 \pm 8$ & $18 \pm 6$ & 0.164 \\
\hline PUFA (g) & $8 \pm 5$ & $8 \pm 4$ & 0.466 \\
\hline Cholesterol (mg) & $252 \pm 79$ & $297 \pm 103$ & 0.163 \\
\hline Water (ml) & $2452 \pm 1045$ & $1850 \pm 957$ & 0.095
\end{tabular}

The results are presented as mean values along with standard deviations. SFA - saturated fatty acids; MUFA - monounsaturated fatty acids; PUFA - polysaturated fatty acids. $p$ (control group vs. study group) t-test for independent means.

Table 3. Changes in the lipid profile in studied women

\begin{tabular}{lccc}
\hline & Control group & Study group & $p$ \\
\hline TC $(\mathrm{mmol} / \mathrm{l})$ & & \\
\hline before & $6.28 \pm 0.66$ & $6.16 \pm 0.77$ & 0.346 \\
\hline after & $6.13 \pm 0.64$ & $5.79 \pm 0.79$ & 0.064 \\
\hline one week after & $6.13 \pm 0.61$ & $5.97 \pm 0.65$ & 0.276 \\
\hline$p^{*}$ & 0.854 & 0.047 & \\
\hline HDL (mmol/l) & & & \\
\hline before & $1.85 \pm 0.40$ & $1.69 \pm 0.26$ & 0.102 \\
\hline after & $1.84 \pm 0.31$ & $1.72 \pm 0.27$ & 0.164 \\
\hline one week after & $1.75 \pm 0.27$ & $1.72 \pm 0.27$ & 0.377 \\
\hline$p^{*}$ & 0.780 & 0.921 & \\
\hline LDL (mmol/l) & & & \\
\hline before & $3.80 \pm 0.67$ & $3.76 \pm 0.69$ & 0.440 \\
\hline after & $3.68 \pm 0.54$ & $3.38 \pm 0.68$ & 0.030 \\
\hline one week after & $3.77 \pm 0.64$ & $3.60 \pm 0.57$ & 0.237 \\
\hline$p^{*}$ & 0.907 & 0.041 & \\
\hline TG (mmol/l) & & & \\
\hline before & $1.25 \pm 0.46$ & $1.34 \pm 0.47$ & 0.311 \\
\hline after & $1.29 \pm 0.42$ & $1.22 \pm 0.44$ & 0.346 \\
\hline one week after & $1.17 \pm 0.22$ & $1.28 \pm 0.47$ & 0.264 \\
\hline$p^{*}$ & 0.831 & 0.740 & \\
\hline
\end{tabular}

The results are presented as mean values along with standard deviations. TG - total cholesterol; HDL - high-density lipoprotein; LDL - low-density lipoprotein; TG - triglycerides. $p$ (control group vs. study group) $t$-test for independent means; $p^{\star}$ (intra-group changes) one-way ANOVA for repeated measurements. Statistically significant results are in bold $(p<0.05)$.

The participants' mean age was $67.0 \pm 0.9$ years. The age means did not differ significantly between the experimental and control groups. Body height was similar in both groups. The performed analysis indicated neither intra- nor inter-group differences (Table 1). The
Table 4. Indicators of fat distribution in the study and control group

\begin{tabular}{lccc}
\hline & Control group & Study group & $p$ \\
\hline WC & & \\
\hline before & $91.37 \pm 6.36$ & $92.78 \pm 8.04$ & 0.663 \\
\hline after & $90.00 \pm 8.03$ & $91.89 \pm 7.28$ & 0.554 \\
\hline$p^{*}$ & 0.258 & 0.190 & \\
\hline HC & & \\
\hline before & $104.00 \pm 6.59$ & $107.36 \pm 5.87$ & 0.200 \\
\hline after & $104.00 \pm 6.69$ & $106.42 \pm 5.63$ & 0.343 \\
\hline$p^{*}$ & 1.000 & 0.003 & \\
\hline A/G ratio & & & \\
\hline before & $1.07 \pm 0.09$ & $1.09 \pm 0.11$ & 0.654 \\
\hline after & $1.09 \pm 0.09$ & $1.09 \pm 0.10$ & 0.942 \\
\hline$p^{*}$ & 0.492 & 0.816 & \\
\hline WHR & & & \\
\hline before & $0.87 \pm 0.02$ & $0.86 \pm 0.04$ & 0.406 \\
\hline after & $0.86 \pm 0.04$ & $0.86 \pm 0.04$ & 0.943 \\
\hline$p^{*}$ & 0.273 & 0.972 & \\
\hline
\end{tabular}

The results are presented as mean values along with standard deviations. WC - waist circumference; $\mathrm{HC}$ - hip circumference; A/G ratio android-to-gynoid ratio (android fat mass/gynoid fat mass); WHR - waist-hip ratio. $p$ (control group vs. study group) $t$-test for independent means, $p^{*}$ (before vs. after) $t$-test for dependent means; statistically significant results are in bold $(p<0.05)$

analysis of the dietary diaries provided by the subjects is presented in Table 2 .

Table 3 includes the analysis results of concentrations of selected cholesterol fractions and triglycerides in the women's blood. A statistically significant decrease in the concentration of total cholesterol and LDL cholesterol was observed in the experimental group (Table 2). The values for the second measurement point in the experimental group differed significantly from the initial values in the group and from the results obtained in the control group. The remaining fractions, i.e. HDL cholesterol and triglycerides, did not undergo a statistically significant change.

In the experimental group, the vibration therapy resulted in a statistically significant decrease in hip circumference. The other indices of adipose tissue distribution did not change significantly in either group (Table 4).

After 21 days of vibration therapy application, a tendency for lowering the atherogenicity indices was observed among the experimental group participants (Tables 5 and 6).

\section{Discussion}


Table 5. Atherogenic indexes of women from the study and control groups

\begin{tabular}{|c|c|c|c|c|c|}
\hline & Control group & $p^{*}$ & Study group & $p^{*}$ & $p$ \\
\hline \multicolumn{6}{|l|}{$\mathrm{Cl}$} \\
\hline before & $3.64 \pm 0.67$ & & $3.69 \pm 0.59$ & & 0.824 \\
\hline after & $3.48 \pm 0.57$ & 0.166 & $3.49 \pm 0.59$ & 0.068 & 0.961 \\
\hline one week after & $3.66 \pm 0.67$ & 0.183 & $3.55 \pm 0.63$ & 0.611 & 0.670 \\
\hline \multicolumn{6}{|l|}{$\mathrm{Cll}$} \\
\hline before & $2.24 \pm 0.49$ & & $2.25 \pm 0.40$ & & 0.952 \\
\hline after & $2.11 \pm 0.45$ & 0.155 & $2.11 \pm 0.48$ & 0.086 & 0.974 \\
\hline one week after & $2.27 \pm 0.52$ & 0.138 & $2.13 \pm 0.44$ & 0.802 & 0.506 \\
\hline \multicolumn{6}{|l|}{ AIP } \\
\hline before & $0.243 \pm 0.26$ & & $0.284 \pm 0.23$ & & 1.000 \\
\hline after & $0.239 \pm 0.18$ & 0.723 & $0.223 \pm 0.22$ & 0.026 & 0.852 \\
\hline one week after & $0.252 \pm 0.19$ & 0.723 & $0.251 \pm 0.23$ & 0.643 & 0.651 \\
\hline \multicolumn{6}{|l|}{ AC } \\
\hline before & $2.64 \pm 0.67$ & & $2.70 \pm 0.59$ & & 0.824 \\
\hline after & $2.48 \pm 0.57$ & 0.166 & $2.50 \pm 0.59$ & 0.068 & 0.962 \\
\hline one week after & $2.66 \pm 0.67$ & 0.183 & $2.55 \pm 0.63$ & 0.611 & 0.670 \\
\hline
\end{tabular}

The results are presented as mean values along with standard deviations. $p^{*}$ (intra-group changes) Cl - Castelli Risk Index I; CII - Castelli Risk Index II; $\mathrm{AC}$ - atherogenic coefficient $-t$-test; AIP - Atherogenic Index of Plasma - Mann-Whitney $U$ test, $p$ (control group vs. study group) $\mathrm{Cl}$, Cll $t$-test, AIP Wilcoxon signed-rank test; statistically significant results are in bold $(p<0.05)$.

Table 6. Effect of vibrotherapy on atherogenic indexes

\begin{tabular}{lcccc}
\hline & Reference range & & $\begin{array}{c}\text { Control group } \\
\text { (percent of women with abnormalities) }\end{array}$ & $\begin{array}{c}\text { Study group } \\
\text { (percent of women with abnormalities) }\end{array}$ \\
\hline $\mathrm{Cl}$ & $<4.0$ & before & 12.5 & 31.5 \\
\hline $\mathrm{Cll}$ & after & 12.5 & 21 \\
\hline & $<3$ & before & 0 & 0 \\
\hline $\mathrm{AlP}$ & after & before & 0 & 0 \\
\hline & $<0.24$ & after & 62.5 & 47.3 \\
\hline $\mathrm{AC}$ & & before & 62.5 & 31.5 \\
\hline & & after & 12.5 & 31.5 \\
\hline
\end{tabular}

The results are presented as percent values. CI - Castelli Risk Index I, CII - Castelli Risk Index II, AIP - Atherogenic Index of Plasma, $\mathrm{AC}$ - atherogenic coefficient

Vibration can be applied as physical activity substitution. The rhythmical contractions and relaxations of skeletal muscles forced by a vibration device induce whole body reactions and activation of numerous muscle groups [16]. In the course of vibration exposition, a conversion of kinetic energy into thermal energy takes place through activation of friction forces. Hettinger was the first to prove the catabolic action of highfrequency vibrations on the adipose tissue in animals [17]. Today it is known that this effect is observed even in animals without the leptin receptor [18]. McGee-Lawrence [18] found that vibration training brought effects comparable to standardised training on a treadmill. Its beneficial impact on body mass change, glucose tolerance, muscle fibre status, and parameters of liver function and steatosis has been proven. However, the applied vibration therapy must be appropriately adjusted; Zhao et al. [19] observed that high-frequency vibrations exerted an adipogenic effect by promoting adipogenesis on the molecular level.

Studies concerning the influence of vibration therapy in the human model have brought inconclusive results. Damijan and Uhryński [20] observed that exposition to general low-frequency vibrations for 19 days decreased the overall adipose tissue amount by up to $2.37 \%$ in $96 \%$ of the sample as compared to $1.12 \%$ in 
$66 \%$ of the control group. The authors explained this effect by pointing out a reaction to mechanical deformation, increase in temperature in a given region of the body, and activation of adipose tissue burning processes as an element of intensified systemic catabolism [20]. Nevertheless, this impact may result from the applied measurement method, i.e. bioelectrical impedance analysis, which only estimates body composition instead of determining its exact values; the results can be additionally falsified in the conditions of altered body temperature and humidity. In the study by Damijan and Uhryński, the participating women were younger, and collective nutrition under sanatorium conditions was applied, which substantially influenced the observed results, especially when one considers the numerous deviations from norms noted in the diets of our study subjects. Sanatorium-stay nutrition, if not individually arranged with a dietician, can also be affected by numerous mistakes [21].

The nutrition analysis based on the dietary diaries provided by the participants revealed many shortcomings in the diets composed freely by the project subjects (Table 1). Among others, energy shortages and protein and fibre shortages were observed, as well as deficient dietary water intake. The statistical analysis proved that nutrition composition mistakes occurred equally often in both groups. All the participating women ate irrationally.

Analysing the results of the assessments of adipose tissue distribution indices presented in the study, one can see a significant influence of oscillatory-cycloid vibration only on the decrease in hip circumferences among women in the experimental group and a tendency of improvement of randomised indices. However, no significant changes in body composition were observed in the participants undergoing vibration massages in the prone position, contrary to research that showed body composition improvement in healthy individuals and type 2 diabetes patients who received therapeutic vibrations in the upright position [22]. According to Sañudo et al. [22], whole body vibration may constitute a modern interventional training, a safe and efficient method to improve body composition, also influencing muscle strength in people unable to perform other forms of physical exercise. With a balanced diet, vibrations additionally stimulating intestinal peristalsis and nutrient absorption function support the process of weight loss [23]. Montero et al. [24] noticed that whole-body vibration training seemed to be associated with three pathways involved in weight loss: inhibition of adipogenesis and reduction of fat mass, increase in energy expenditure, and increase in muscle mass. With the vibration stimulus applied in the abdominal area, we did not obtain the body composition improvement observed in the previous studies. Although this was not the issue of our re- search, the participants reported more frequent bowel movements after vibration therapy. The reason could be a vibration-induced increase in intestinal peristalsis, which has already been observed with other forms of vibration stimulus application [23].

Vibration massage applied for 21 days lowered the levels of total cholesterol and LDL cholesterol, as well as atherogenicity indices among women with evidence of hypercholesterolaemia (LDL above $3 \mathrm{mmol} / \mathrm{l}$ ), which seems a challenging outcome. Atherogenicity indices calculated on the basis of the lipid profile allow us to assess the concentrations of particular elements of the lipid profile. Exceeding the relevant normal values for each indicator is associated with a higher risk of atherosclerosis and, consequently, of cardiovascular diseases [25]. Although vibration applied as an isolated modification of lifestyle improves the lipid profile, its beneficiary effect was not maintained for a longer period: the last measurement point (a week after the vibration stimulus withdrawal) revealed results that did not differ statistically from the initial values. An interesting issue is whether prolonging the action of the vibrating stimulus would extend its effect.

In the guidelines concerning physical activity, the American College of Sports Medicine and the American Diabetes Association recommend at least 150 minutes per week of moderate aerobic activity $(60-85 \%$ of maximum heart rate), resulting in weekly energy expenditure at the level of 1000-2000 kcal [26]. However, despite its simplicity, this is not a commonly used means of preventing and treating metabolic diseases. Frequently indicated barriers include lack of time, as well as social (upbringing and negative experiences), psychological, and biological (e.g. neurological) conditions [27]. In such situations, a solution may be the use of vibrations, in accordance with the indication that vibration training is an equivalent to physical effort, without the inconveniences associated with, among others, the locomotor system overload. This can help solve the problem of low physical activity in people who cannot or do not want to perform exercise for a variety of reasons.

It should be emphasised that all participants completed the presented study (four violated the intervention protocol because of symptoms of infectious diseases), which indirectly points at the acceptability of the method and lack of effects that could discourage prolonged use of the therapy. The study design (21-day therapy) was supposed to imitate sanatorium conditions or a recreational stay, and in this form, for specific patients, it may prove to be an effective and safe therapy. This, however, requires sound scientific evidence and further testing among different target groups.

\section{Conclusions}


Oscillatory-cycloid vibration applied regularly for 21 days has a beneficial impact on lowering the level of total cholesterol and LDL cholesterol, as well as a decrease in atherogenicity indices in women aged over 65 years with diagnosed hypercholesterolaemia.

\section{Disclosure}

The authors report no conflict of interest.

\section{References}

1. Gorodeski G. Impact of the menopause on the epidemiology and risk factors of coronary artery heart disease in women. Exp Gerontol 1994; 29: 357-375.

2. Zdrojewski T, Solnica B, Cybulska B, et al. Prevalence of lipid abnormalities in Poland. The NATPOL 2011 survey. Kardiol Pol 2016; 74: 213-223.

3. Biercewicz M, Szrajda J, Haor B, Kędziora-Kornatowska K. Polypharmacy - an important issue in elderly patients care. Probl Pielęg 2012; 20: 102 105.

4. Jankowski P. Treatment of hypercholesterolemia in 2013. Chor Serca i Naczyń 2013; 10: 141-150.

5. Saulicz M, Saulicz E, Knapik A, et al. Impact of physical activity and fitness on the level of kinesiophobia in women of perimenopausal age. Prz Menopauzalny 2016; 15: 104-111.

6. Cochrane D. Vibration exercise: the potential benefits. Int J Sports Med 2011; 32: 75-99.

7. Zaidell L, Mileva K, Sumners D, Bowtell J. Experimental evidence of the tonic vibration reflex during whole-body vibration of the loaded and unloaded leg. PLoS ONE 2013; 8: e85247.

8. Chanou K, Gerodimos V, Karatrantou K, Jamurtas A. Wholebody vibration and rehabilitation of chronic diseases: a review of the literature. J Sports Sci Med 2012; 11: 187-200.

9. Zafar H, Alghadir A, Anwer S, Al-Eisa E. Therapeutic effects of wholebody vibration training in knee osteoarthritis: a systematic review and meta-analysis. Arch Phys Med Rehabil 2015; 96: 1525-1532.

10. Yang X, Zhou Y, Wang P, et al. Effects of whole body vibration on pulmonary function. functional exercise capacity and quality of life in people with chronic obstructive pulmonary disease: a systematic review. Clin Rehabil 2016; 30: 419-431.

11. Damijan Z. Trening wibracyjny w rehabilitacji kardiologicznej. Acta BioOpt Inform Med 2009; 4: 356-360.

12. del Pozo-Cruz B, Alfonso-Rosa R, del Pozo-Cruz J, et al. Effects of a 12-wk whole-body vibration based intervention to improve type 2 diabetes. Maturitas 2014; 77: 52-58.

13. Szponar L, Wolnicka K, Rychlik E. Album fotografii produktów i potraw. IŻŻ, Warszawa 2000.

14. Biernat E, Stupnicki R, Gajewski A. International Physical Activity Ques tionnaire (IPAQ) - Polish version. Wychow Fiz Sport 2007; 51: 47-54.

15. Sujatha R, Kavitha S. Atherogenic indices in strokepatients: A retrospective study. Iran J Neurol 2017; 16: 78-82.

16. Rittweger J. Vibration as an exercise modality: how it may work, and what its potential might be. Eur J Appl Physiol 2010; 108: 877-904.

17. Hettinger T, Muller E. Seasonal course of trainability of musculature. Int Z Angew Physiol 1956; 16: 90-94.

18. McGee-Lawrence M, Wenger K, Misra S, et al. Whole-Body Vibration Mimics the Metabolic Effects of Exercise in Male Leptin Receptor-Deficient Mice. Endocrinology 2017; 158: 1160-1171.

19. Zhao Q, Lu Y, Gan X, Yu H. Low magnitude high frequency vibration promotes adipogenic differentiation of bone marrow stem cells via P38 MAPK signal. PLoS ONE 2017; 12: e0172954.

20. Damijan Z, Uhryński A. The Effect of General Low Frequency Vibration on EnergyBalance of a Human Being. Acta Psych Pol A 2013; 123: $970-$ 973.

21. Pilch W, Bałajewicz G. The evaluation of the energy balance of health resort visitors during 21-days staying in the sanatorium. Rocz Panstw Zakl Hig 2009: 60: 69-73.
22. Sañudo B, Alfonso-Rosa R, Del Pozo-Cruz B, et al. Whole body vibration training improves leg blood flow and adiposity in patients with type 2 diabetes mellitus. Eur J Appl Physiol 2013; 113: 2245-2252.

23. Ron Y, Halpern Z, Safadi R, et al. Safety and efficacy of the vibrating capsule, an innovative non-pharmacological treatment modality for chronic constipation. Neurogastroenterol Motil 2015; 27: 99-104.

24. Montero C, Cuevas M, Collado P. Whole - body vibration training as complement to programs aimed at weight loss. Nutr Hosp 2013; 28: 1365-1371.

25. Friedrich M, Goluch-Koniuszy Z. The effectiveness of nutritional education among women aged 60-85 on the basis of anthropometric parameters and lipid profiles. Rocz Panstw Zakl Hig 2017; 68: 253-260.

26. Colberg S, Sigal R, Fernhall B, et al. Exercise and type 2 diabetes: the American College of Sports Medicine and the American Diabetes Association: joint position statement. Diabetes Care 2010; 33: e147-e167.

27. Grochowska E, Jarzyna R. Physical activity in the prevention and treatment of diseases of affluence--the key role of AMP-activated protein kinase (AMPK). Postepy Hig Med Dosw 2014; 68: 1114-1128. 